\title{
O acionamento das lâmpadas e das persianas em função da percepção da iluminação na entrada da sala
}

\author{
The activation of lamps and blinds according to the \\ perception of lighting at the room entrance
}

\section{Americo Hiroyuki Hara Fernando Oscar Ruttkay Pereira}

\section{Resumo \\ $\mathbf{E}$} ste estudo trata sobre o acionamento da iluminação artificial e das persianas em função da percepção da iluminação do indivíduo/observador quando este se encontra na porta de entrada de uma sala. O objetivo do trabalho foi relacionar a percepção da iluminação, o acionamento das lâmpadas e das persianas. A metodologia consistiu na aquisição de dados experimentais por meio de imagem HDR e de questionários aplicados em 41 participantes. As variáveis analisadas foram a luminância média da janela (Lja) e os índices de ofuscamento DGP e DGI, pois elas estavam correlacionadas com a percepção da iluminação, o acionamento das lâmpadas e das persianas. O índice DGP se mostrou pouco sensível ao subestimar valores frente a situações evidentes de ofuscamento. Para o DGI, o intervalo definido para a situação de lâmpadas desligadas e persianas abertas foi entre 18,4 $\pm 1,0$ e 23,8 \pm 1,0, quando a percepção da iluminação da sala foi considerada "clara". Para Lja, o intervalo para a situação de lâmpadas desligadas e de persianas abertas foi entre $1.636 \pm 302 \mathrm{~cd} / \mathrm{m}^{2}$ a $4.981 \pm 419 \mathrm{~cd} / \mathrm{m}^{2}$. Conclui-se que os intervalos podem servir de base para construção de modelos comportamentais a serem usados em simulações computacionais para estudar o consumo de energia elétrica nas edificações e para auxiliar o desenvolvimento de projetos de arquitetura visando o aproveitamento da luz natural.

Palavras-chave: Iluminação artificial e natural. Percepção da iluminação. Atitude do usuário. Imagens HDR.

\section{Abstract}

This article considers that visual perception influences the switching on electric lighting and blinds closing. The objective is to study the relationship of visual perception from the door position, with the switching on electric lighting and with the blinds down position. The methodology consisted of experiments conducted with 41 participants to inquire about their visual perception, and switch light on and blinds closing events data. By using an HDR image technique, the mean window luminance (Lja), DGP and DGI were analyzed because of their correlation with the visual perception, the switching lighting on and the blinds down position. The DGP index presented little sensitivity because of their values that did not demonstrate apparent visual discomfort situations. For the DGI, the range set for the situation of the lighting off and blinds opened was between $18.4 \pm$ 1.0 and $23.8 \pm 1.0$, and the visual perception of the room is "bright". To mean window luminance (Lja), between $1636 \pm 302 \mathrm{~cd} / \mathrm{m}^{2}$ and $4981 \pm 419 \mathrm{~cd} / \mathrm{m}^{2}$, the lighting was off, and the blinds opened. The conclusion is that the proposed intervals of DGI and the mean window luminance can be used to construct behavioral models to support the electric energy use simulation in buildings and to enhance the daylight design of interior space.

Recebido em 06/10/19 Aceito em 05/02/20
Keywords: Artificial lighting. Daylight. Visual perception. User attitude. HDR images. 


\section{Introdução}

O acionamento das lâmpadas e das persianas tem impacto significativo no consumo de energia elétrica de uma edificação. Entender como o usuário interage com esses sistemas de iluminação considerando sua percepção de claro e escuro sobre os espaços internos possibilita a elaboração de projetos mais acertados.

As explicações sobre o uso da iluminação artificial são diversas, enquanto algumas pesquisas indicam que está vinculado com a disponibilidade de iluminação natural no recinto (HUNT, 1979; LYNES; LITTLEFAIR; SLATER, 1997; LOVE, 1998; REINHART; WALKENHORST, 2001; SILVA; LEAL; ANDERSEN, 2013); outros sugerem que está associado com a ocupação do espaço (ASSAF; PEREIRA, 2003; YUN; KIM; KIM, 2012).

No entanto, o acionamento das persianas em escritórios está relacionado com a incidência solar direta (RUBIN; COLLINS; TIBBOTT, 1978; REA, 1984; MANICCIA et al., 1999) e o desconforto visual na superfície de trabalho (BOYCE; HUNTER; HOWLETT, 2003; INKAROJRIT, 2005; VAN DEN WYMELENBERG; INANICI; JOHNSON, 2010). Ademais, Van Den Wymelenberg, Inanici e Johnson (2010) identificaram que o usuário permite a incidência solar direta pela janela desde que não incida sobre sua área de trabalho.

Van Den Wymelenberg (2014) descreveu lacunas nas pesquisas de desconforto visual, dentre as quais: a necessidade de uma padronização na metodologia de análise de dados, procedimentos de captura e calibração de imagens de elevado contraste (imagem $\mathrm{HDR}^{1}$ ) de forma consistente e reproduzível, e também a organização de instrumentos de coleta de dados subjetivos.

Dessa forma, este estudo se baseia na hipótese de que o acionamento da iluminação artificial e das persianas ocorre em função da percepção da iluminação quando o indivíduo/observador se encontra na porta de entrada da sala, pois é quando avalia as condições de iluminação do espaço e atua sobre os sistemas de iluminação almejando seu conforto visual.

As condições de iluminação foram analisadas mediante medições da iluminância vertical e a geração de imagem HDR para a obtenção das luminâncias e dos índices de ofuscamento com base nos estudos realizados por Inkarojrit (2005), Jacobs (2007), Van Den Wymelenberg, Inanici e Johnson (2010).

Os índices DGI e DGP indicam a ocorrência de desconforto visual por contraste e considera a possibilidade de ofuscamento gerada por fontes grandes, como as janelas, por exemplo (JAKUBIEC; REINHART, 2012).

A caracterização da percepção da luminosidade (variações de claro e escuro) sobre as condições de iluminação na sala foi realizada por meio de um questionário baseado nos estudos de Iwata et al. (1990), Eklund e Boyce (1995), Pineault e Dubois (2008) e Van Den Wymelenberg, Inanici e Johnson (2010). Além disso, por envolver seres humanos, a pesquisa foi submetida e aprovada pelo comitê de ética (protocolo n. 50831215.7.0000.0121).

O objetivo geral desta pesquisa foi correlacionar as variáveis fotométricas e de desconforto visual com a percepção da iluminação e o acionamento das lâmpadas e das persianas pelo usuário.

\section{Materiais e método}

A fim de caracterizar a percepção da iluminação no espaço de permanência e relacionar com o acionamento das lâmpadas e das persianas, definiu-se o plano da porta de entrada da sala como a posição quando o usuário avalia as condições de iluminação e decide acionar as lâmpadas e/ou fechar as persianas.

Na posição descrita, foram levantadas sequencialmente a iluminância vertical, 16 fotos para a geração de imagens HDR, caracterização do campo visual e a percepção da iluminação para cada participante.

As medições de iluminância vertical para caracterizar a densidade de luz que chega à face do indivíduo/observador foram realizadas a $1,65 \mathrm{~m}$ de altura do piso com Hobo U-12. O Hobo foi fixado à câmera fotográfica e ajustado para ficar aprumado, com a ajuda de outro suporte (Figura 1). Os valores de iluminância do sensor Hobo U-12 apresentaram diferenças em torno de $10 \%$ em comparação com os do luxímetro Minolta, percentuais tolerados conforme recomendações de Hiscoks (2011).

${ }^{1}$ HDR é acrônimo de high dynamic range, e diz respeito a imagens cujo contraste é mais próximo da percepção visual humana. 


\section{Figura 1 - Suporte para prender o Hobo à câmera para medição de iluminância vertical na face do} indivíduo/observador

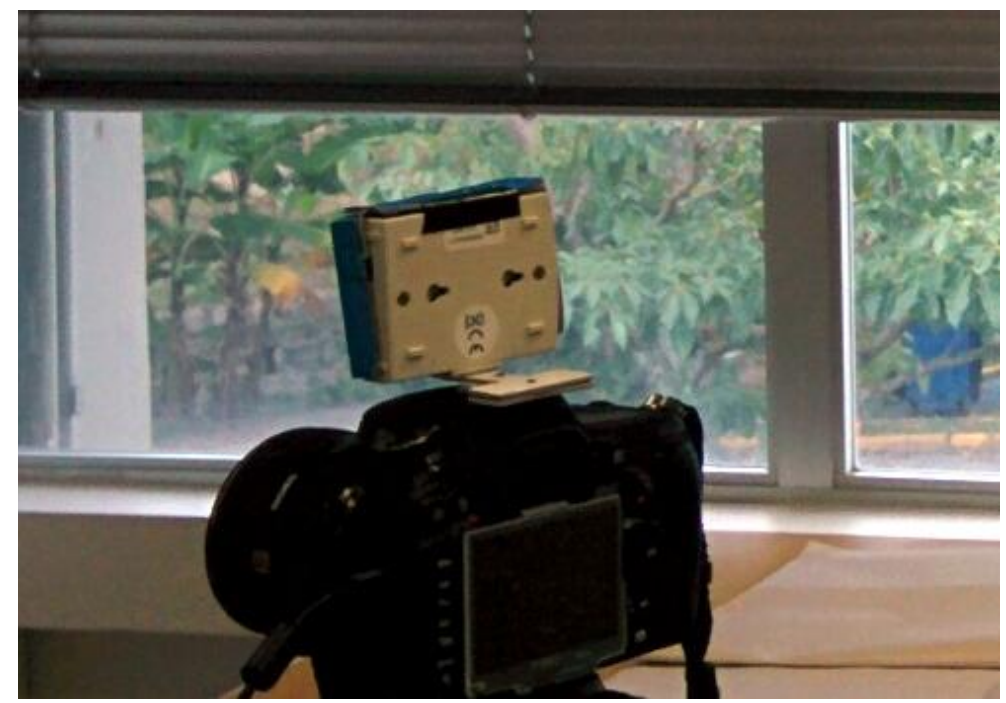

A câmera fotográfica semiprofissional (Nikon D7000) com uma lente grande angular de $180^{\circ}$ foi acomodada em um tripé para ficar na altura de $1,65 \mathrm{~m}$ e conectada a um computador portátil para tirar uma sequência de 16 fotos de um mesmo ponto de vista em diferentes tempos de exposição, fundamentais para gerar uma imagem HDR. Os tempos de exposição das 16 fotos são 4s, 2s, 1s, 1/2s, 1/4s, 1/8s, 1/15s, 1/30s, 1/60s, $1 / 125 \mathrm{~s}, 1 / 250 \mathrm{~s}, 1 / 500 \mathrm{~s}, 1 / 1.000 \mathrm{~s}, 1 / 2.000 \mathrm{~s}, 1 / 4.000 \mathrm{~s}, 1 / 8.000 \mathrm{~s}$, conforme recomendam Jakubiec et al. (2016), e foram obtidas utilizando-se o programa Sofortbild, disponível somente para a plataforma MacOs.

Posteriormente, as 16 fotos foram combinadas para gerar uma imagem HDR no programa Photosphere. A calibração do programa Photosphere para a câmera Nikon D7000 foi realizada inserindo no aplicativo o valor da luminância de um determinado ponto da cena medida por meio de um luminancímetro para servir de referência na imagem HDR, conforme Jakubiek et al. (2016).

As imagens HDR foram utilizadas para obter as luminâncias e índices de ofuscamento por meio do programa Hdrscope, conforme propõem Kumaragurubaran e Inanici (2013) e Kumaragurubaran (2019). Os valores de luminâncias obtidos das imagens HDR geradas no programa Photosphere e carregadas no Hdrscope foram semelhantes (HARA, 2018).

A percepção da iluminação pelo indivíduo/observador foi realizada por meio de questionários estruturados na escala Likert de 5 pontos, sendo 1-Muito_Escuro; 2-Escuro; 3-Nem_Escuro/Nem_Claro; 4-Claro e 5Muito_Claro, para a avaliação visual das condições de iluminação do espaço e do brilho das superfícies (piso, parede, teto e janela).

O Quadro 1 sintetiza os instrumentos com as características e as finalidades utilizadas na pesquisa.

Um estudo piloto foi realizado com 5 indivíduos para verificar o entendimento das questões, a pontuação da escala Likert, os procedimentos para a coleta e o tratamento de dados.

Para o experimento, a sala, localizada em Laguna, SC, foi escolhida por apresentar ar condicionado e persianas verticais na janela. A janela da sala está orientada para nordeste, o que permite a insolação no período da tarde e possibilita o estudo da situação de desconforto visual. A mesma janela ocupa em torno de $60 \%$ da área total do fechamento, sendo o restante $40 \%$ parede opaca, branca, com refletância aproximada de 0,8 (Figura 2).

A sala foi climatizada a uma temperatura média de $24{ }^{\circ} \mathrm{C}$ e ambientada com mobiliário de escritório, com duas mesas, duas cadeiras estofadas, dois armários, quadro e lixeira.

A Figura 3 apresenta a planta baixa esquemática com as dimensões dos espaços e foto da sala representando a perspectiva dos participantes da pesquisa. O ponto A indica a posição onde os participantes/observadores se posicionaram para responder o questionário de percepção da iluminação e o registro das fotos para gerar as imagens HDR. 
Para cada experimento, as condições iniciais da sala foram de lâmpadas desligadas e persianas abertas, ou seja, o espaço estava iluminado somente com luz natural. Além disso, cada participante acionou as lâmpadas conforme sua necessidade e as persianas foram fechadas pelo pesquisador, se assim fosse solicitado, porém sem a possibilidade de mantê-las parcialmente abertas. A situação das lâmpadas (ligadas/desligadas) e das persianas (abertas/fechadas) foram registradas por meio de fotos e anotações do pesquisador.

Os experimentos foram realizados nos dias 30/05, 05/06, 06/06, 12/06, 15/08 e 22/08 de 2017, devido à maior incidência solar na janela. No total, 41 indivíduos participaram da pesquisa, entre estudantes de arquitetura e técnicos administrativos que foram selecionados ao acaso. O tempo do experimento com cada indivíduo foi em média de 20 minutos.

\section{Quadro 1 - Relação dos equipamentos utilizados na pesquisa}

\begin{tabular}{|l|l|}
\hline \multicolumn{1}{|c|}{ Instrumento } & \multicolumn{1}{c|}{ Características/Finalidade } \\
\hline Hobo light U12-012 & $\begin{array}{l}\text { Datalogger para o registro da iluminância vertical, temperatura do ar e } \\
\text { umidade relativa. }\end{array}$ \\
\hline Luminancímetro Minolta & Aferição das luminâncias das imagens HDR. \\
\hline Câmera fotográfica & Nikon DSLR D7000 para registro de fotos. \\
\hline Lente grande angular de $180^{\circ}$ & $\begin{array}{l}\text { Lente Sigma } 4.5 \mathrm{~mm} \text { F2.8 EX DC HSM Circular Fisheye para registro } \\
\text { do campo visual. }\end{array}$ \\
\hline Tripé para câmera fotográfica & $\begin{array}{l}\text { Deixar a câmera estática e à altura de 1,5 m do piso para a captura de } \\
\text { fotos. }\end{array}$ \\
\hline $\begin{array}{l}\text { Programa Sofortbild (versão } \\
\text { 1.2.11) }\end{array}$ & $\begin{array}{l}\text { Programa livre para controlar a câmera fotográfica por computador e } \\
\text { guardar as fotos. Sistema operacional MacOs. }\end{array}$ \\
\hline $\begin{array}{l}\text { Programa Photosphere (versão } \\
\text { 1.8.16U) }\end{array}$ & $\begin{array}{l}\text { Programa livre para geração de imagens HDR e medição de luminância. } \\
\text { Sistema operacional MacOs. }\end{array}$ \\
\hline $\begin{array}{l}\text { Programa Hdrscope (versão } \\
\text { 1.0.0.0) }\end{array}$ & $\begin{array}{l}\text { Programa livre para obtenção de luminâncias, contrastes e índices de } \\
\text { desconforto visual. Sistema operacional Windows. }\end{array}$ \\
\hline Questionário & $\begin{array}{l}\text { Questões na escala Likert para avaliação da percepção da iluminação e } \\
\text { indicação de acionamento das lâmpadas e das persianas. }\end{array}$ \\
\hline
\end{tabular}

Figura 2 - Indicação do local (círculo em vermelho), em Laguna, SC

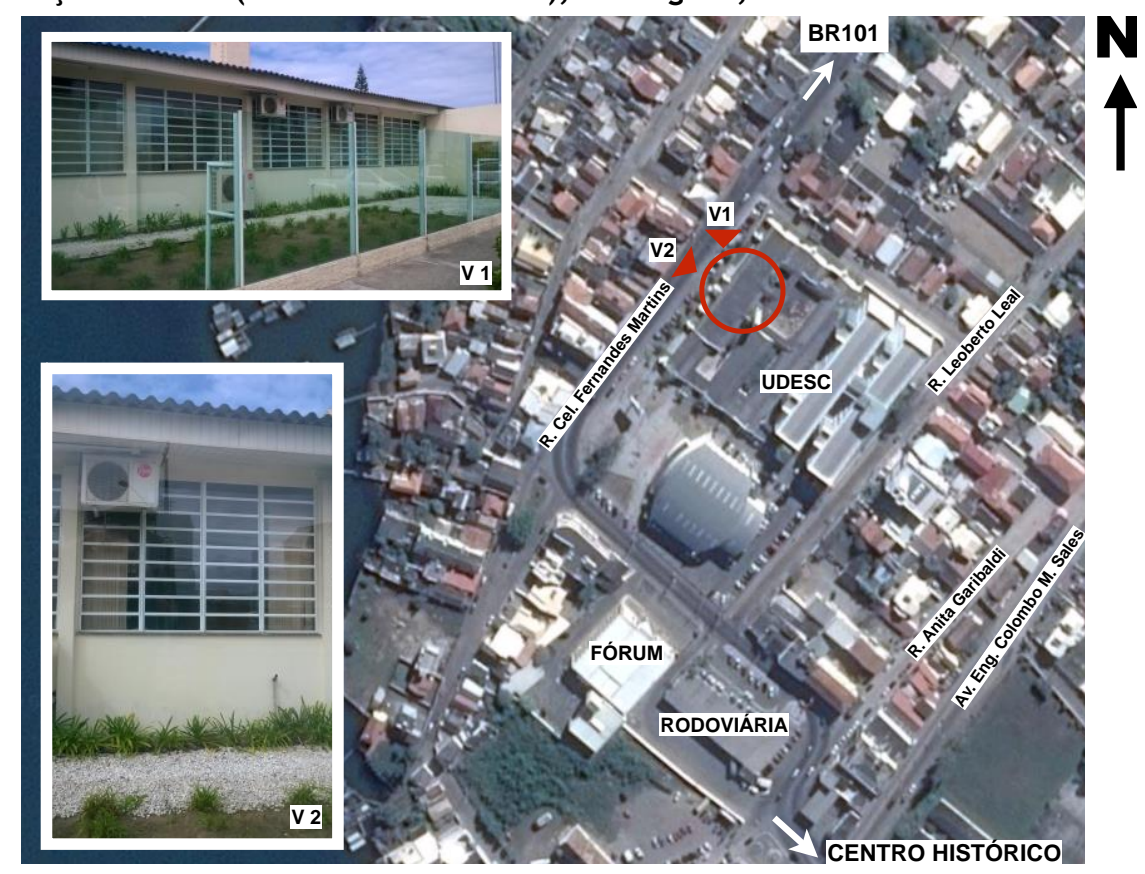

Fonte: adaptado de Google Maps (2019). 
Figura 3 - Planta baixa sem escala da sala e do corredor (medidas em metro) e, abaixo, imagem da sala mobiliada e a janela ao fundo

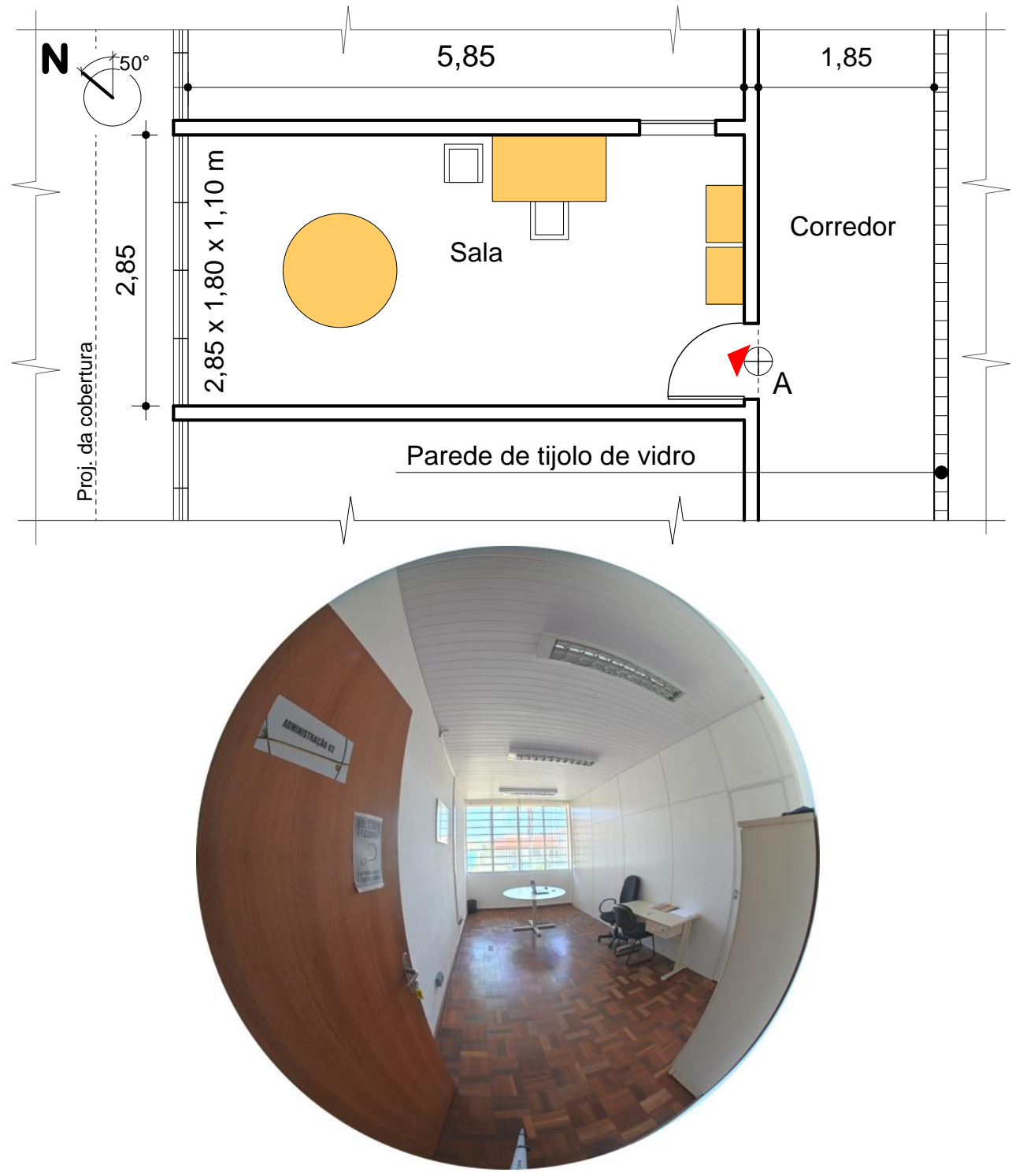

\section{Análise dos dados}

No ponto $\mathrm{A}$, as variáveis consideradas na pesquisa foram a iluminância vertical a 1,65 m do piso (Ev), luminância média da cena (Lcena), luminância média da janela (Lja), a luminância média da mesa (Lmesa), os índices de ofuscamento DGP e DGI (Figura 3).

Para realizar as análises de correlação linear das variáveis quantitativas, os dados qualitativos foram transformados em números ordinais (MEDRI, 2011). As análises das variáveis qualitativas e das quantitativas foram realizadas segundo os coeficientes de correlação de Person $(r)$ para as variáveis discretas, e de Kendall ( $\tau$ ), para as categóricas, com $p<0,05$, sendo uma forte correlação, se $r>0,75$, média, se $r>0,5$ e fraca, se $r<0,5$ (DORIA FILHO, 1999).

Além disso, por meio das análises de variância (ANOVA), buscou-se identificar as médias das variáveis fotométricas que caracterizam a situação de lâmpadas ligadas e desligadas e de persianas abertas e fechadas. Os testes estatísticos foram realizados por meio do programa Jasp (JASP..., 2018).

A análise dos resultados correlacionou a percepção da iluminação com o acionamento das lâmpadas e das persianas. Além disso, buscou-se evidenciar as variáveis e os limites que caracterizam a relação entre a 
percepção da iluminação e o acionamento das lâmpadas e das persianas, para tanto foram estudadas as relações entre:

(a) a percepção da iluminação em função da luminância média da janela e dos índices DGP e DGI;

(b) o acionamento das lâmpadas em função da luminância média da janela e dos índices DGP e DGI;

(c) o acionamento das persianas em função da luminância média da janela e dos índices DGP e DGI;

(d) a percepção da iluminação e o acionamento das lâmpadas e das persianas;

(e) a relação da percepção da iluminação, o acionamento das lâmpadas e das persianas em função do índice DGI; e

(f) a relação da percepção da iluminação, o acionamento da iluminação artificial e das persianas em função da luminância média da janela (Lja).

As variáveis consideradas na pesquisa foram a luminância média da janela e os índices de ofuscamento DGI e DGP. Os valores de DGI e DGP foram classificados segundo o Quadro 2.

\section{Análise e discussão dos resultados}

Os resultados obtidos das análises indicaram correlação (Kendall - $\tau$ ) praticamente moderada entre a percepção da iluminação com o acionamento das lâmpadas $(\tau=-0,47, p=0,001)$ e das persianas $(\tau=0,49, p$ $<0,001)$. Isso indica que os eventos de ligar as lâmpadas e de fechar as persianas estão relacionados com a percepção que os usuários têm sobre a iluminação do espaço.

As correlações das variáveis com a percepção da iluminação, o acionamento das lâmpadas e o fechamento das persianas são apresentados no Quadro 3.

As variáveis que apresentaram correlação simultânea com a percepção da iluminação, o acionamento das lâmpadas e o fechamento das persianas foram a luminância da janela (Lja) e os índices de ofuscamento DGI e DGP, sendo assim, não foi plausível a inserção dos resultados referentes à iluminância vertical (Ev), luminância média da cena (Lcena) e luminância média da mesa (Lmesa).

Dessa forma, considerou-se Lja, DGI e DGP como as variáveis de ligação para evidenciar limites que caracterizassem a percepção da iluminação como "Muito_Escuro", "Escuro", "Nem_Escuro/Nem_Claro", "Claro" e "Muito_Claro" frente ao acionamento das lâmpadas e ao fechamento das persianas.

\section{Percepção da iluminação na sala em função da luminância média da janela (Lja) e dos índices de ofuscamento DGP e DGI}

A Tabela 1 apresenta os coeficientes de correlação de Kendall $(\tau)$, bem como a luminância média da janela (Lja) e os índices DGP e DGI. Destaca-se que não houve avaliação da sala como "Muito_Escura", ou seja, nenhum participante/observador considerou a sala como "Muito Escura", e para ilustrar a percepção da iluminação da sala como "Escura", "Nem_Escura/Nem_Clara", "Clara" e "Muito_Clara" em função das luminâncias dentro do campo visual, apresenta-se quatro imagens em cores falsas (Figura 4).

Quadro 2 - Intervalo dos valores dos índices de ofuscamento DGI e DGP e a sensação visual

\begin{tabular}{|c|c|c|c|c|}
\hline & Imperceptível & Perceptível & Desconfortável & Intolerável \\
\hline DGI & $<18$ & $18-24$ & $24-31$ & $>31$ \\
\hline DGP & $<0,35$ & $0,35-0,40$ & $0,40-0,45$ & $>0,45$ \\
\hline
\end{tabular}

Fonte: Jakubiec e Reinhart (2012).

Quadro 3 - Correlação da percepção da iluminação, acionamento das lâmpadas e fechamento das persianas em função das variáveis Lja, DGP e DGI

\begin{tabular}{|l|c|c|c|}
\hline \multicolumn{1}{|c|}{ Variáveis } & $\begin{array}{c}\text { Percepção da } \\
\text { iluminação }(\tau)\end{array}$ & $\begin{array}{c}\text { Acionamento das } \\
\text { lâmpadas }\end{array}$ & $\begin{array}{c}\text { Fechamento } \\
\text { das persianas }\end{array}$ \\
\hline Luminância média da janela (Lja) & $0,634 * * *$ & $-0,334, p=0,033$ & $0,720 * * *$ \\
\hline DGP & $0,674 * * *$ & $-0,451, p=0,003$ & $0,566 * * *$ \\
\hline DGI & $0,604 * * *$ & $-0,399, p=0,01$ & $0,539 * * *$ \\
\hline
\end{tabular}

Nota: $\tau$ : coeficiente de correlação de Kendall; $\mathrm{e}^{* * *} p<0,001$. 
Tabela 1 - Correlação da percepção da iluminação da sala $(\tau)$ em função da luminância média da janela (Lja) e dos índices de ofuscamento DGP e DGI

\begin{tabular}{c|c|c|c|c|c}
\hline $\begin{array}{c}\text { Variável [unidade } \\
\text { de medida] }\end{array}$ & $\boldsymbol{\tau}$ & Escuro & $\begin{array}{c}\text { Nem_Escuro/ } \\
\text { Nem_Claro }\end{array}$ & Claro & Muito_Claro \\
\hline $\begin{array}{c}\text { Luminância média da } \\
\text { janela - Lja [cd/m²] }\end{array}$ & 0,634 & $68 \pm 18$ & $737 \pm 228$ & $3291 \pm 416$ & $4591 \pm 655$ \\
\hline DGP & 0,674 & $0,00 \pm 0,0$ & $0,08 \pm 0,0$ & $0,25 \pm 0,0$ & $0,30 \pm 0,0$ \\
\hline DGI & 0,604 & $10,9 \pm 1,3$ & $17,7 \pm 0,8$ & $22,0 \pm 0,4$ & $23,9 \pm 1,1$ \\
\hline Amostra (N) & & 5 & 6 & 22 & 8 \\
\hline
\end{tabular}

Nota: $\tau$ : coeficiente de correlação de Kendall. Os valores estão expressos com a média \pm e.p.m $(\mathrm{N}=41), p<0,001$ (teste Tukey-Kramer).

Figura 4 - Percepção da iluminação da sala em função da luminância

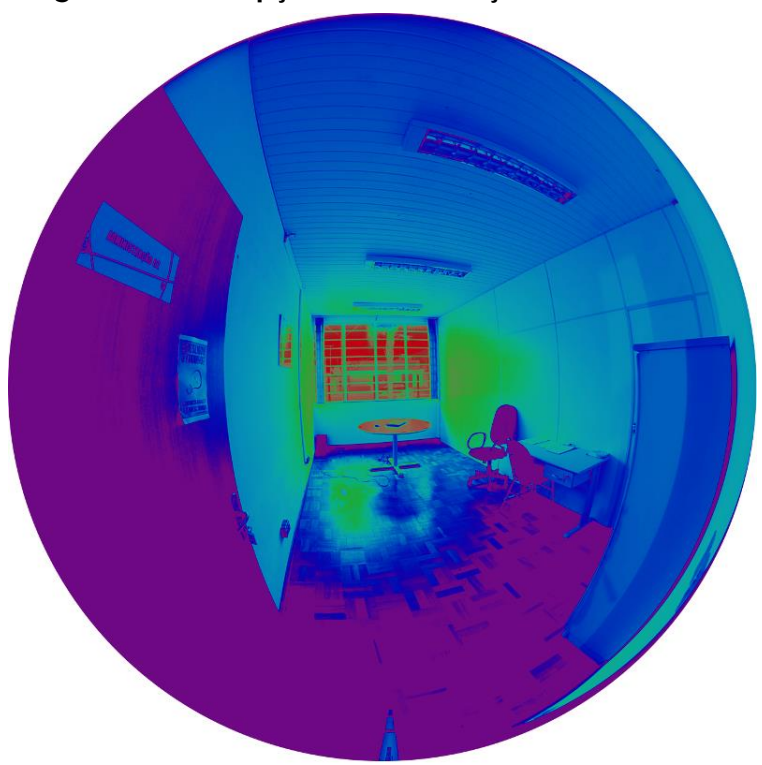

(a) "Escuro"

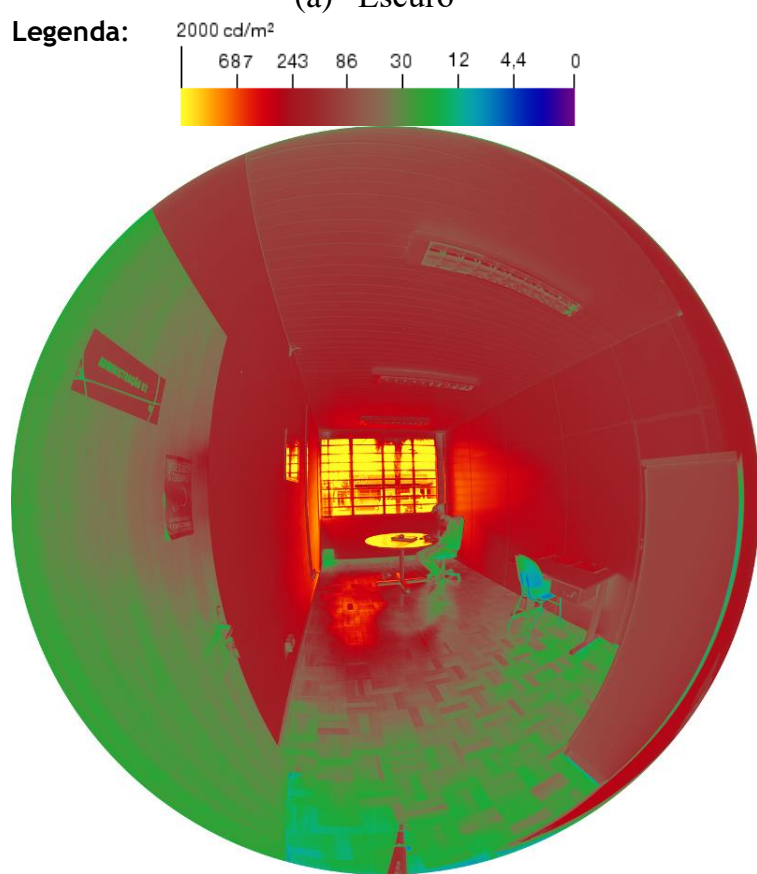

(c) "Claro"

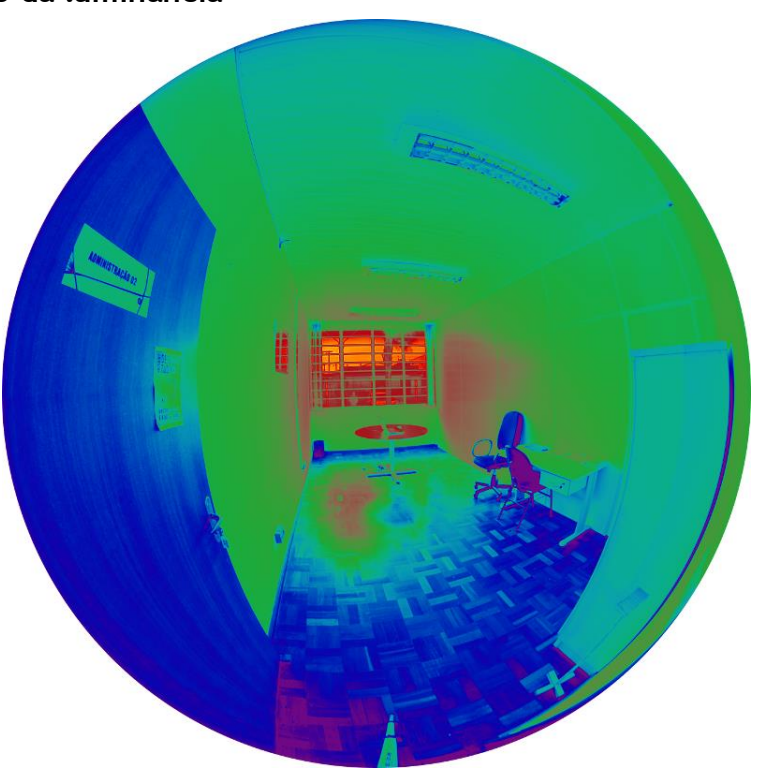

(b) "Nem_Escuro/Nem_Claro"

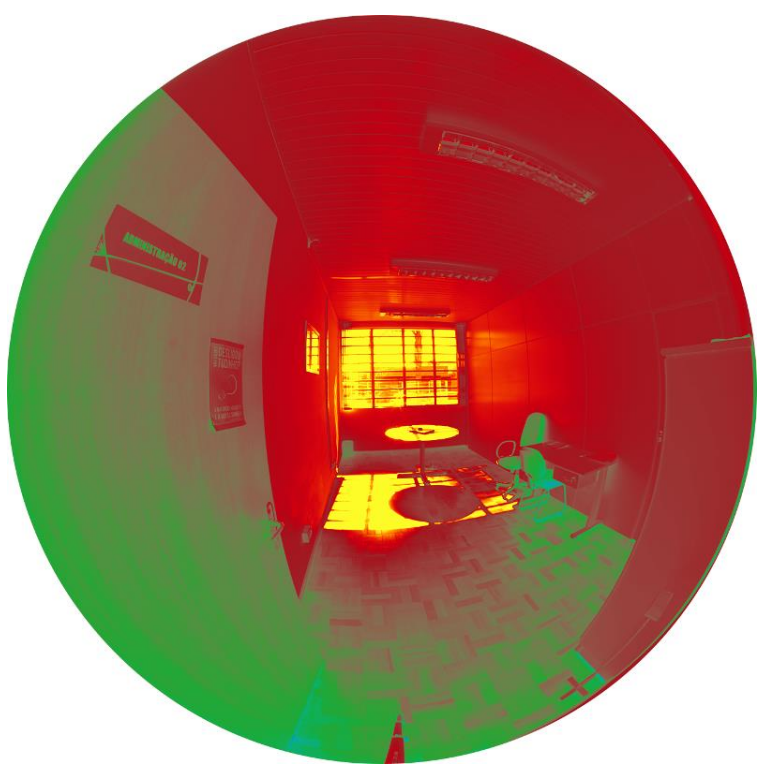

(d) "Muito_Claro" 
Observa-se que o brilho da janela influencia na distribuição da iluminação natural pela sala. A percepção da iluminação da sala como "Escura" ocorre quando há pouco brilho da janela, enquanto para "Muito_Claro" há ingresso da radiação solar pela abertura.

O índice de ofuscamento DGP apresentou correlação média $(0,674)$ com a percepção da iluminação. Entretanto, verificou-se que os valores de DGP localizaram-se na zona definida como "imperceptível”, sem indicação de situação de desconforto visual ("perceptível", "desconfortável" ou "intolerável") mesmo quando os participantes avaliaram a sala como sendo "Claro" ou "Muito_Claro" para situações com incidência solar direta sobre a mesa e no piso (Figura 5).

Assim, nota-se nesse experimento que o índice DGP não representa adequadamente a situação de desconforto visual ou ofuscamento, pois os valores permaneceram na faixa do "Imperceptível". A explicação razoável para os baixos valores de DGP é que o ângulo sólido $(\omega)$ da fonte causadora de ofuscamento deste estudo foi menor em comparação com o de Wienold e Christoffersen (2006). Isso porque para as outras variáveis envolvidas na equação do DGP, a luminância, a iluminância vertical e a position index, os valores foram relativamente semelhantes.

Para o índice DGI, os pontos que definem a percepção da iluminação refletiram, de forma coerente, a sensação visual (Figura 6).

O gráfico da Figura 6 pode ser mais bem compreendido quando associado com o da Figura 7, que relaciona a percepção da iluminação, valores de DGI calculados e a sensação visual.

A relação entre a percepção da iluminação da sala e o DGI permitiu evidenciar que "Escuro" (DGI $\leq 10,9 \pm$ 1,3) definiu a sensação visual "Imperceptível"; "Nem_Escuro/Nem_Claro" (DGI $\leq 17,7 \pm 08$ ), corresponde à transição de "Imperceptível" para "Perceptível"; "Claro" (DGI 22,0 \pm 0,4), caracterizada como "Perceptível", e; para "Muito_Claro", o (DGI $\geq 24,0 \pm 1,1)$, na transição entre "Perceptível" para "Desconfortável". Nota-se que não houve valor de DGI que representa a sensação "Intolerável" (DGI > 31). Nesse quesito, observa-se que o DGI subestima a sensação "Intolerável”.

A diferença entre a percepção "Claro" e "Muito_Claro" é pouco significativa, porém o cenário e suas implicações no que se refere ao uso das persianas são evidentes. Enquanto para a percepção "Claro" as persianas costumam ficar abertas, pois, em geral, não há incidência solar direta (Figura 4c), para "Muito_Claro" há radiação solar sobre a mesa (Figura 4d) e, consequentemente, o fechamento delas.

Para a luminância média da janela (Lja), tem-se o baixo brilho da janela $\left(68 \pm 18 \mathrm{~cd} / \mathrm{m}^{2}\right)$ que caracteriza a percepção da iluminação de "Escuro". Nessa situação, é bastante provável que a iluminação artificial se torne necessária.

Figura 5 - Valores de DGP calculados em função da percepção da iluminação dos participantes e a indicação da sensação visual

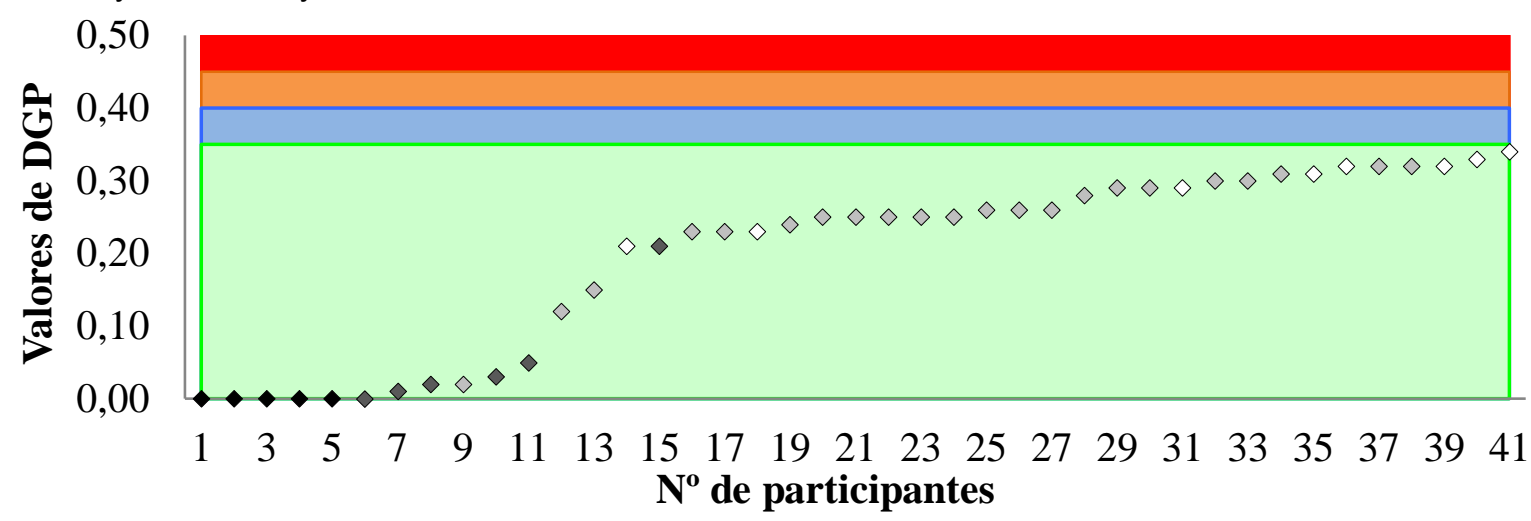

Legenda: Sensação visual

\begin{tabular}{|l|l|}
\hline Imperceptível & DGP $<18$ \\
\hline Perceptível & $18<$ DGP $<24$ \\
\hline Desconfortável & $24<$ DGP $<31$ \\
\hline Intolerável & DGP $>31$ \\
\hline
\end{tabular}

Legenda: Percepção da iluminação

\begin{tabular}{|l|l|}
\hline & Escuro \\
\hline$\searrow$ & Nem_escuro/Nem_claro \\
\hline$\searrow$ & Claro \\
\hline$\bigcirc$ & Muito_claro \\
\hline
\end{tabular}


Figura 6 - Valores de DGI calculados em função da percepção da iluminação dos participantes e a indicação da sensação visual

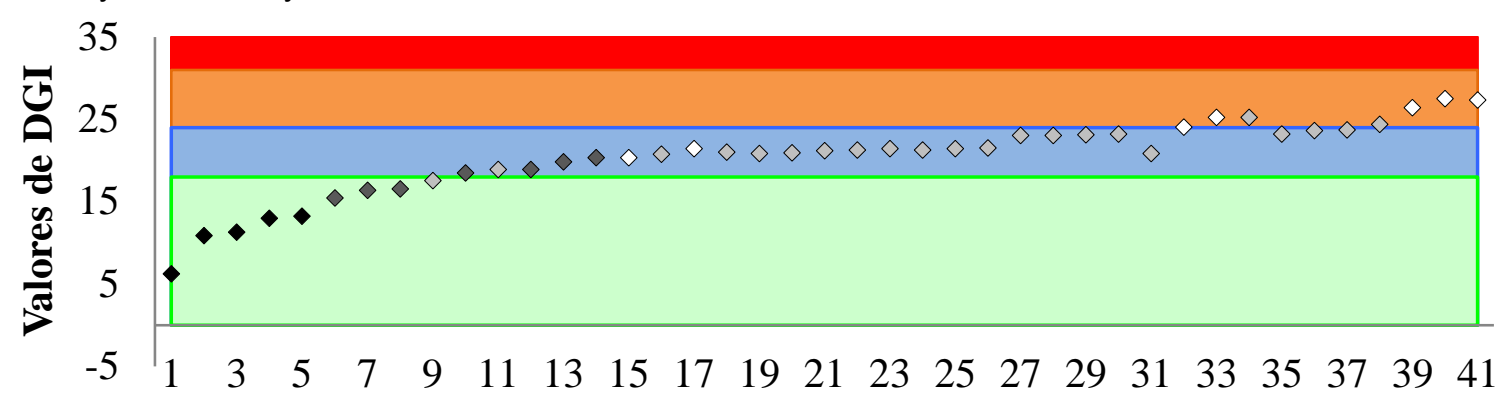

\section{$\mathbf{N}^{\circ}$ de participantes}

Legenda: Sensação visual

Legenda: Percepção da iluminação

\begin{tabular}{|l|l|}
\hline Imperceptível & DGP $<18$ \\
\hline Perceptível & $18<$ DGP $<24$ \\
\hline Desconfortável & $24<$ DGP $<31$ \\
\hline Intolerável & DGP $>31$ \\
\hline
\end{tabular}

\begin{tabular}{|l|l|}
\hline & Escuro \\
\hline$\searrow$ & Nem_Escuro/Nem_Claro \\
\hline$\searrow$ & Claro \\
\hline$\searrow$ & Muito_Claro \\
\hline
\end{tabular}

Figura 7 - Percepção da iluminação em função do índice DGI

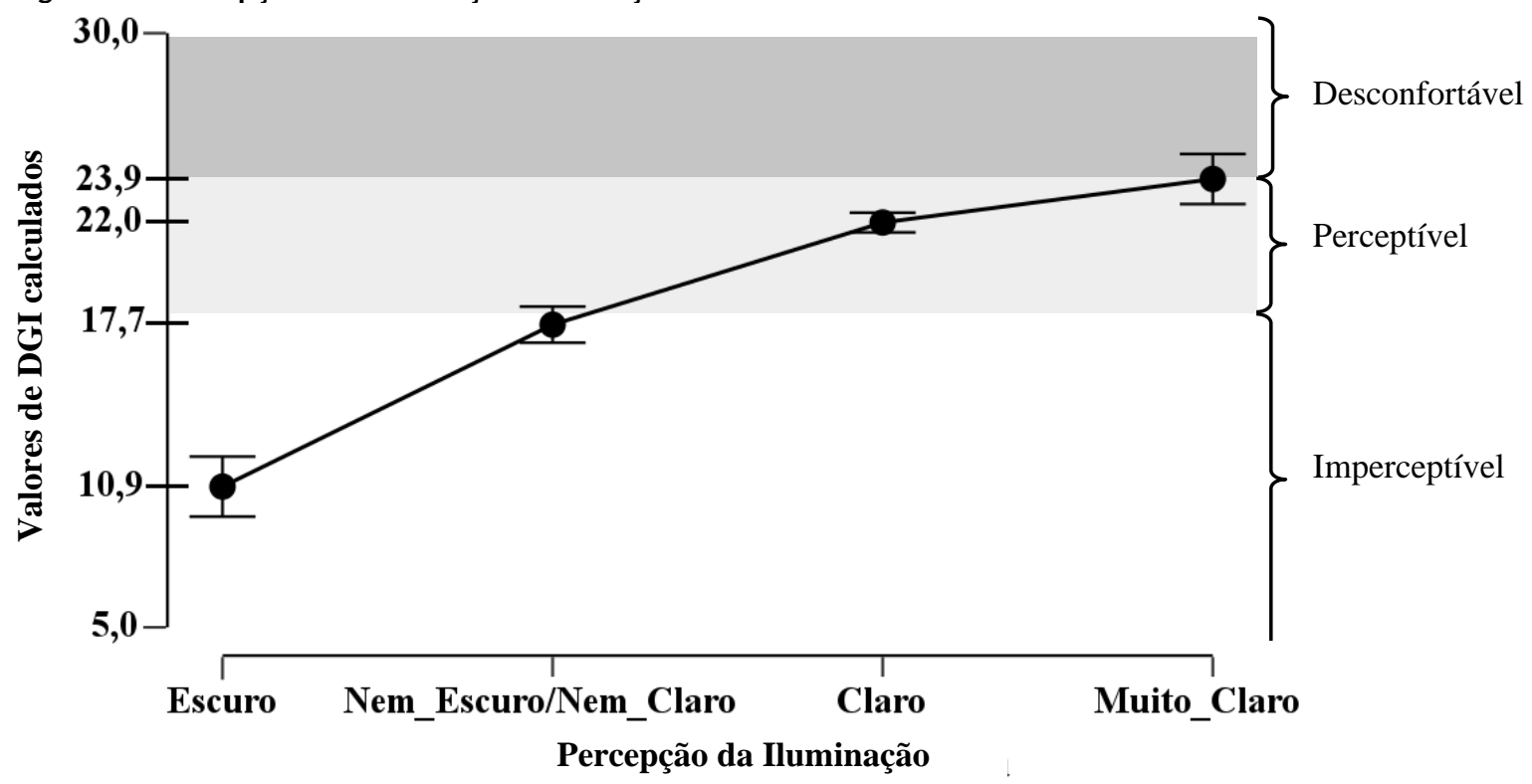

Nota: os valores estão expressos com a média \pm e.p.m $(\mathrm{N}=41), p<0,05$ (teste Tukey-Kramer).

Também é notável a variação entre as percepções de "Nem-Escuro/Nem_Claro" (737 $\left.\pm 228 \mathrm{~cd} / \mathrm{m}^{2}\right)$ e "Claro" (3.291 $\left.\pm 416 \mathrm{~cd} / \mathrm{m}^{2}\right)$, uma diferença em torno de $2.500 \mathrm{~cd} / \mathrm{m}^{2}$, conforme se observa no gráfico da Figura 8. Nesse intervalo, o acionamento das lâmpadas e das persianas foi pouco significativo, sendo demonstrado nas próximas duas seções.

Para Lja $>4.600 \mathrm{~cd} / \mathrm{m}^{2}$ que caracteriza a percepção "Muito_Claro", verifica-se que o elevado brilho da janela é desconfortável e, consequentemente, se reflete no fechamento das persianas.

Considerando as características das superfícies do espaço assim como sua dimensão e da abertura, os valores de DGI e da luminância da janela (Lja) são relativamente confortáveis para o indivíduo/observador na entrada da sala para o intervalo definido como "Nem_Escuro/Nem_Claro" a "Claro", ou seja, $18<$ DGI $<22$ e $800<\mathrm{Lja}<3300 \mathrm{~cd} / \mathrm{m}^{2}$, valores que definem a sensação visual na faixa considerada "Perceptível”. 


\section{Acionamento das lâmpadas em função da luminância média da janela (Lja) e dos índices de ofuscamento DGP e DGI}

A Tabela 2 foi confeccionada para relacionar os índices DGP, DGI e a luminância média da janela (Lja) em função do acionamento das lâmpadas pelo usuário.

Destaca-se que o sinal negativo dos coeficientes de correlação dos índices DGP e DGI e da luminância média da janela (Lja) indica que essas variáveis respondem de forma inversamente proporcional ao acionamento das lâmpadas (Tabela 2), ou seja, a elevação dos índices DGP e DGI e da luminância da janela sugere que as lâmpadas permanecerão desligadas.

No caso do índice DGP, os valores não indicaram adequadamente as situações de desconforto visual. Repara-se pelos valores de DGP constantes na Tabela 2 que, tanto para ligar as lâmpadas quanto para deixálas desligadas, ambos se encontram no intervalo da sensação visual definida como "Imperceptível" (DGP < 0,35; Quadro 2).

Para o índice DGI, conforme pode ser observado no gráfico da Figura 9, tem-se que as lâmpadas foram mantidas desligadas quando o índice DGI foi 22,0 $\pm 0,8$ ("Perceptível"), e foram ligadas quando DGI foi 18,4 \pm 1,0 (entre "Imperceptível" e "Perceptível"). Sendo assim, parece que o índice DGI descreve o acionamento das lâmpadas melhor que o DGP.

Quanto à luminância média da janela (Lja), as lâmpadas foram ligadas quando Lja foi de $1.945 \pm 502 \mathrm{~cd} / \mathrm{m}^{2}$, e permaneceram desligadas quando Lja foi de $3.430 \pm 444 \mathrm{~cd} / \mathrm{m}^{2}$ (Figura 10).

Objetivando relacionar o acionamento da iluminação artificial com a percepção da iluminação, pode-se dizer que os valores de DGI e da luminância média da janela que configuram a situação de ligar as lâmpadas correspondem à de um espaço considerado "Nem_Escuro/Nem_Claro".

Além disso, partindo-se desse resultado, se a percepção da iluminação da sala for "Escura" ou "Muito_Escura", é evidente que haverá o acionamento das lâmpadas.

Figura 8 - Percepção da iluminação em função da luminância média da janela (Lja)

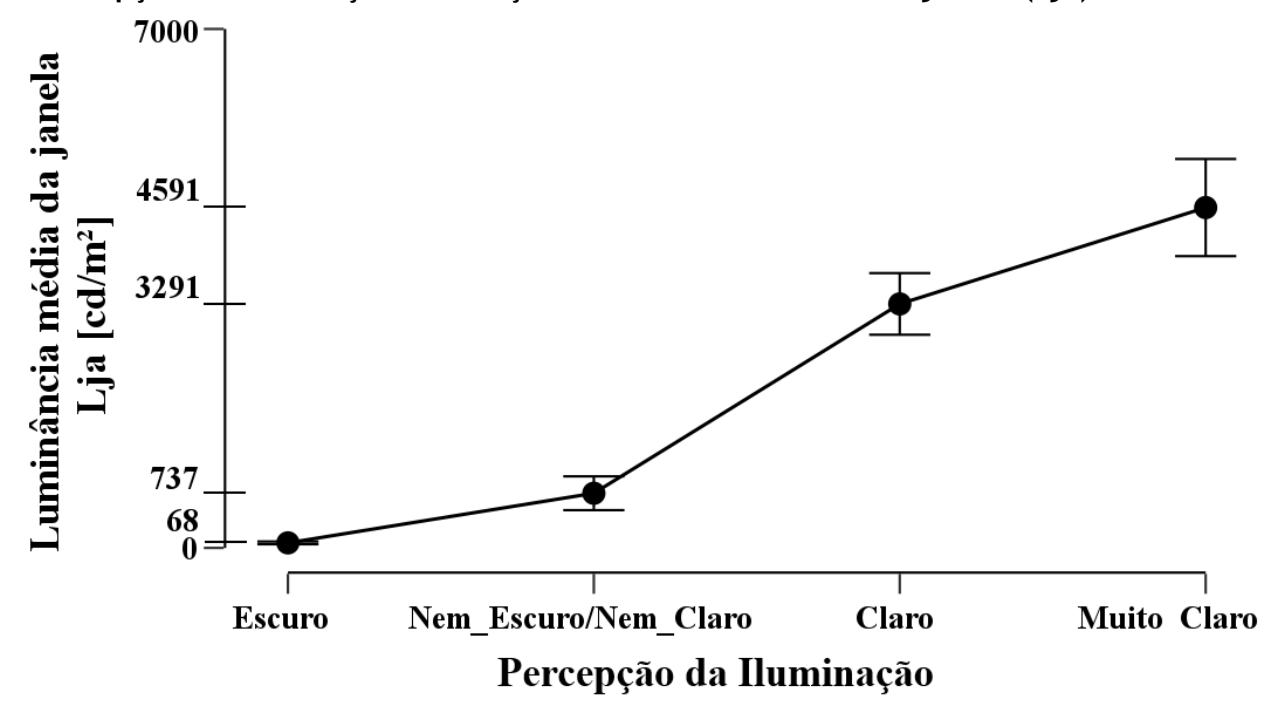

Nota: os valores estão expressos com a média \pm e.p.m $(\mathrm{N}=41), p<0,05$ (teste Tukey-Kramer).

Tabela 2 - Correlação entre o acionamento das lâmpadas, a luminância média da janela (Lja), e os índices de ofuscamento DGP e DGI

\begin{tabular}{l|c|c|c}
\hline \multicolumn{1}{c|}{ Variável [unidade de medida] } & $\boldsymbol{r}(\boldsymbol{p}<\mathbf{0 , 0 5})$ & Desligado & Ligar \\
\hline Índice DGP & $-0,451^{* *}$ & $0,25 \pm 0,0^{* *}$ & $0,15 \pm 0,0^{* *}$ \\
\hline Índice DGI & $-0,399^{* *}$ & $22 \pm 0,8^{* *}$ & $18,4 \pm 1,0^{* *}$ \\
\hline Luminância Média da Janela $-\mathrm{Lja}\left[\mathrm{cd} / \mathrm{m}^{2}\right]$ & $-0,334^{* *}$ & $3.430 \pm 444^{* *}$ & $1.945 \pm 502^{* *}$ \\
\hline \multicolumn{2}{c|}{ Amostra $(\mathrm{N})$} & 23 & 18 \\
\hline
\end{tabular}

Nota: os valores são apresentados com a média \pm e.p.m $(\mathrm{N}=41)$, com ${ }^{* *} p<0,05$ (teste Tukey-Kramer). 
Figura 9 - Acionamento das lâmpadas em função do índice de ofuscamento DGI

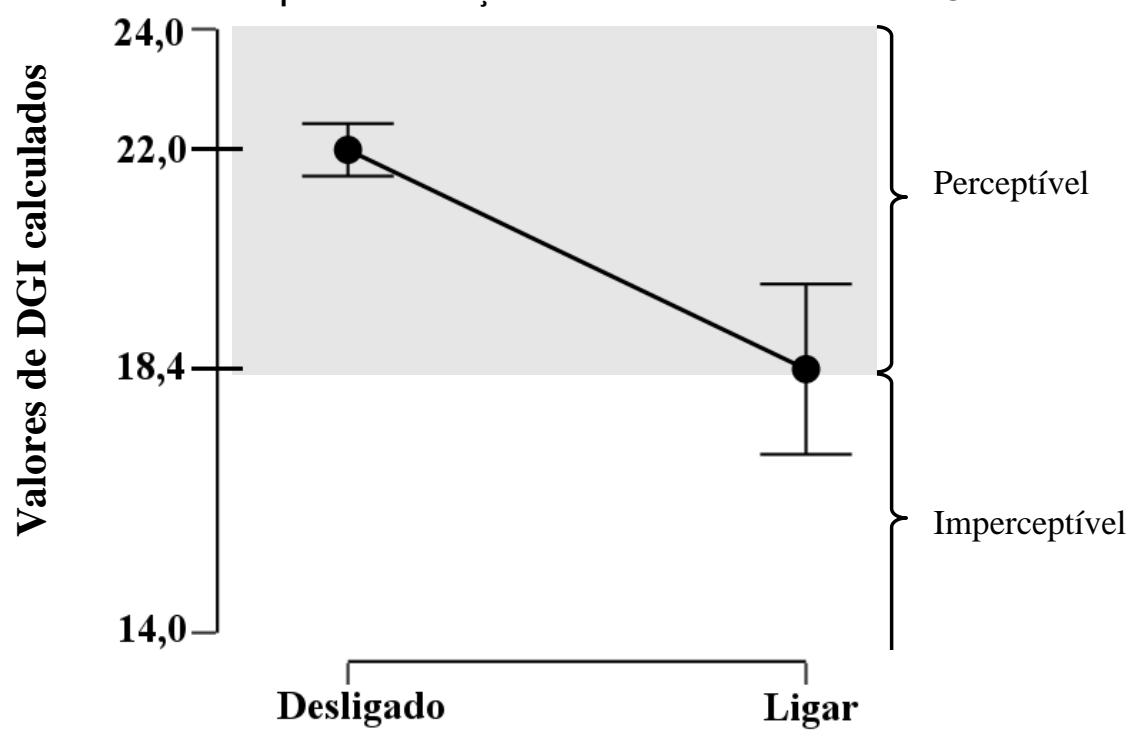

Acionamento das lâmpadas

Nota: os valores estão expressos com a média \pm e.p.m $(\mathrm{N}=41), p<0,05$ (teste Tukey-Kramer).

Figura 10 - Acionamento das lâmpadas em função da luminância média da janela

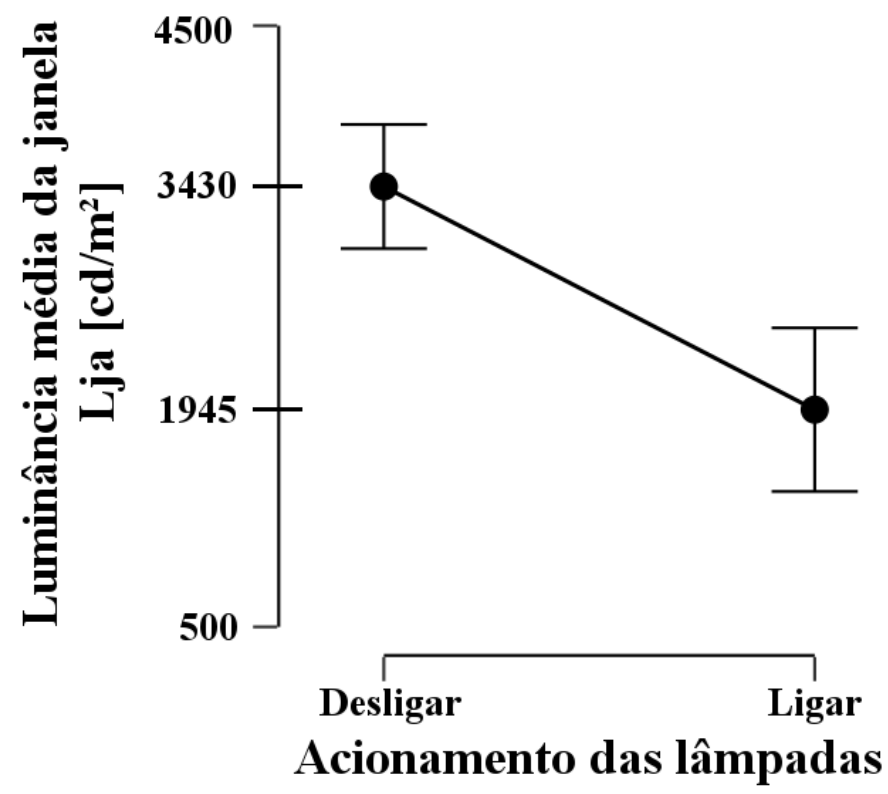

Nota: os valores estão expressos com a média \pm e.p.m $(\mathrm{N}=41), p<0,05$ (teste Tukey-Kramer).

Por outro lado, é importante compreender que a capacidade de adaptação do sistema visual humano não é ilimitada, de modo que há situações de desconforto visual que podem ser caracterizadas, pelo DGI e Lja, embora existam outras variáveis que possam ser exploradas. A ocorrência de desconforto visual pode ser observada pelo acionamento das persianas, conforme será abordado a seguir.

\section{Acionamento das persianas em função da luminância média da janela e dos índices de ofuscamento DGP e DGI}

A Tabela 3 foi confeccionada para relacionar os índices DGP e DGI e a luminância média da janela (Lja) em função do acionamento das persianas pelos usuários. Observa-se também, que não houve indicação de 
sensação "Desconfortável" (DGP < 0,40, Quadro 2) ou "Intolerável (DGP > 0,45). Dessa forma, os valores de DGP não representaram adequadamente as situações de desconforto visual.

A Figura 11 apresenta a situação de persianas abertas e fechadas em função da luminância média da janela. Identifica-se uma variação significativa entre os valores que definem as duas situações, em torno de 3.500 $\mathrm{cd} / \mathrm{m}^{2}$.

No caso do índice DGI, a diferença entre a situação de persianas abertas e fechadas situa-se na faixa considerada como "Perceptível", embora os valores que caracterizam as duas situações encontram-se, respectivamente, nos limites inferior $(18,7 \pm 0,8)$ e superior $(23,8 \pm 1,0)$, conforme se observa na Figura 12.

Portanto, o intervalo definido como "Perceptível" aparentemente refere-se à situação quando as condições de iluminação na sala são confortáveis.

\section{Percepção da iluminação da sala e o acionamento das lâmpadas e das persianas}

O acionamento das lâmpadas ocorreu quando a percepção da iluminação da sala foi "Nem_Escuro/Nem_Claro" e elas permaneceram desligadas quando foi "Claro" (Figura 13).

A Figura 14 trata do acionamento das persianas em função da percepção da iluminação, nota-se que as persianas foram fechadas quando a percepção da iluminação foi "Nem_Escuro/Nem_Claro" e, permaneceram abertas quando foi "Claro".

Tabela 3 - Correlação entre o acionamento das persianas e as variáveis fotométricas e os índices de ofuscamento

\begin{tabular}{|c|c|c|c|}
\hline Variável [unidade de medida] & $r(p<0,005)$ & Aberto & Fechar \\
\hline Luminância da Janela - Lja [cd//m²] & $0,720 * *$ & $1636 \pm 302 * *$ & $4981 \pm 419 * *$ \\
\hline Índice DGP & $0,566 * *$ & $0,16 \pm 0,0 * *$ & $0,3 \pm 0,0 * *$ \\
\hline Índice DGI & $0,539 * *$ & $18,7 \pm 0,8 * *$ & $23,8 \pm 1,0 * *$ \\
\hline \multicolumn{2}{|l|}{ Amostra $(\mathrm{N})$} & 27 & 14 \\
\hline
\end{tabular}

Nota: os valores estão expressos com a média \pm e.p.m (N=41), $p<0,05$ (teste Tukey-Kramer).

Figura 11 - Acionamento das persianas em função da luminância média da janela

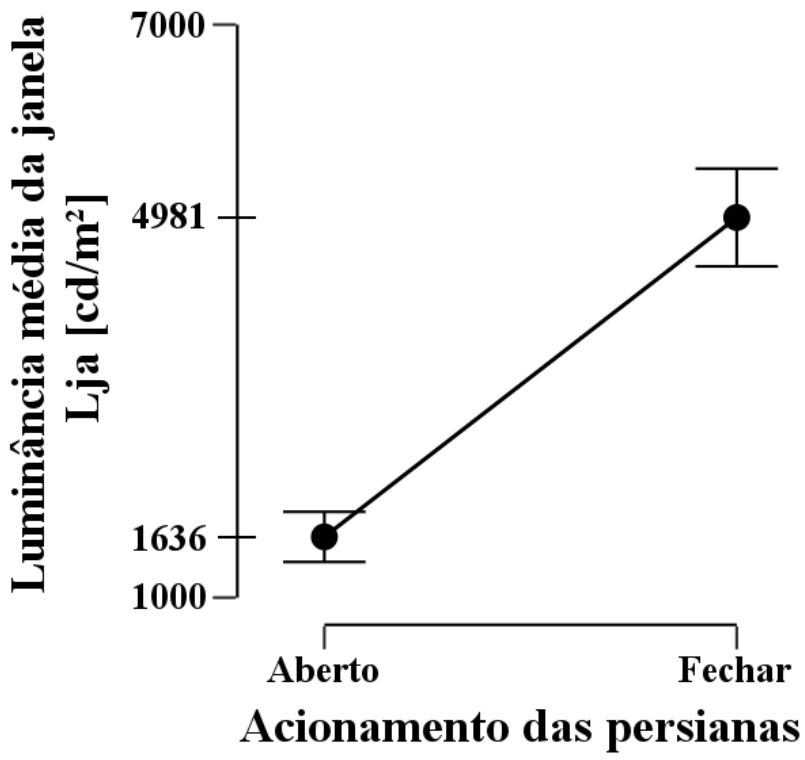

Nota: os valores estão expressos com a média \pm e.p.m $(\mathrm{N}=41), p<0,05$ (teste Tukey-Kramer). 
Figura 12 - Acionamento das persianas em função do índice de ofuscamento DGI

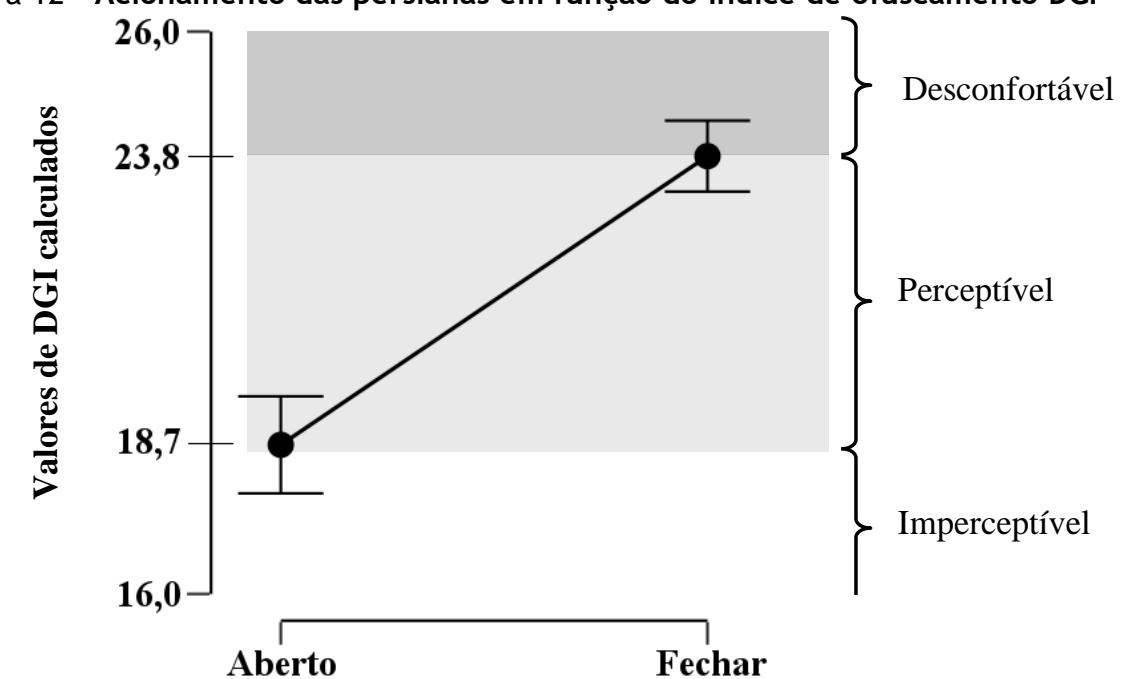

Acionamento das persianas

Nota: os valores estão expressos com a média \pm e.p.m $(\mathrm{N}=41), p<0,05$ (teste Tukey-Kramer).

Figura 13 - Percepção da iluminação da sala e o acionamento das lâmpadas

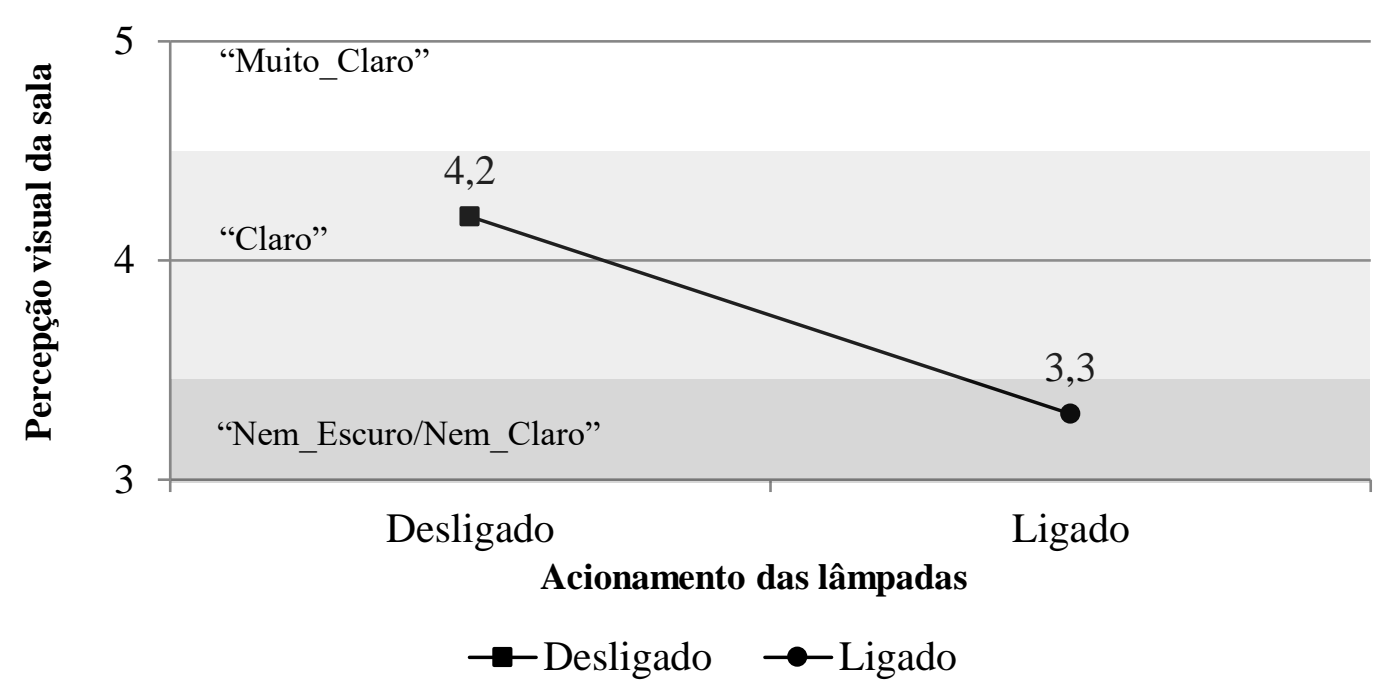

Nota: Legenda:

Faixa cinza "Nem_Escuro/Nem_Claro" = 3;

Faixa cinza claro "Claro" = 4; e

Faixa branca "Muito_Claro" $=5$. 
Figura 14 - Percepção da iluminação da sala e o acionamento das persianas

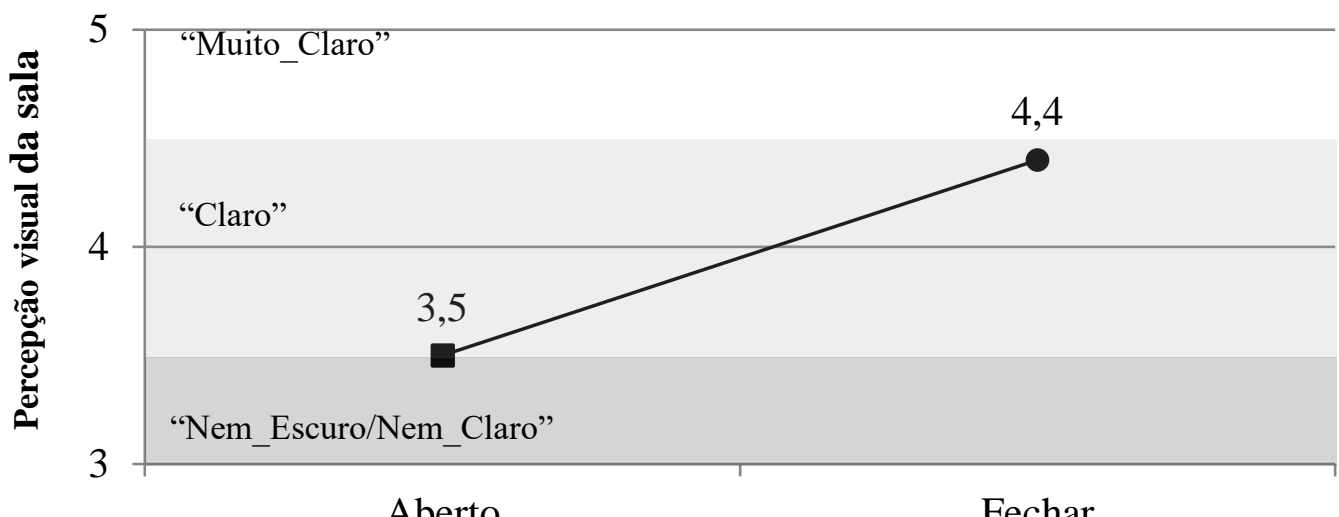

Aberto

Fechar

\author{
Acionamento das persianas \\ $\rightarrow$ - Aberto $\rightarrow-$ Fechar \\ Nota: Legenda: \\ Faixa cinza "Nem_Escuro/Nem_Claro" = 3; \\ Faixa cinza claro "Claro" = 4; e \\ Faixa branca "Muito_Claro"= 5.
}

Ao comparar os gráficos da Figura 13 e Figura 14, constata-se que enquanto o acionamento da iluminação artificial ocorreu quando a sala se mostrou "Nem_Escuro/Nem_Claro", o fechamento das persianas foi determinado pela percepção de "Claro" a "Muito_Claro" ocasionado principalmente pelo excesso de luz natural proveniente da janela.

\title{
Relação da percepção da iluminação, o acionamento das lâmpadas e das persianas em função do índice DGI
}

Com base nos resultados apresentados, identifica-se que em relação à percepção da iluminação, o índice DGI foi de 10,9 \pm 1,3 para "Escuro", de 17,7 \pm 0,8 para "Nem_Claro/Nem_Escuro", de 22,0 \pm 0,4 para "Claro" e de 23,9 \pm 1,0 para "Muito_Claro". No que tange ao acionamento das lâmpadas, quando o DGI foi $18,4 \pm 1,0$, elas eram ligadas e, quando DGI foi $22,0 \pm 1,0$, elas se mantiveram desligadas.

No que se refere ao uso das persianas, o fechamento ocorreu quando o DGI foi 23,8 $\pm 1,0$, ao passo que elas costumavam ficar abertas quando o DGI foi de 18,7 $\pm 0,8$. Dessa forma, os intervalos para o índice DGI que definem o acionamento das lâmpadas e das persianas são apresentados conforme o Quadro 4.

Portanto, na porta da sala em questão, para o índice DGI entre 18,4 $\pm 1,0$ e 23,8 $\pm 1,0$, cujo intervalo corresponde à sensação visual de "Perceptível", as lâmpadas costumavam permanecer desligadas e as persianas abertas. De certa forma, esse intervalo indica o máximo aproveitamento da iluminação natural no início da ocupação.

\section{Relação da percepção da iluminação, o acionamento da iluminação artificial e das persianas em função da luminância média da janela (Lja)}

Conforme exposto, o acionamento das lâmpadas pelos participantes ocorreu quando a luminância média na janela foi de $1945 \pm 502 \mathrm{~cd} / \mathrm{m}^{2}$, ou seja, quando a sala foi considerada "Muito_Escura", "Escura" e "Nem_Escura/Nem_Clara".

Por sua vez, as lâmpadas permaneceram desligadas quando a luminância média da janela foi de $3430 \pm 444$ $\mathrm{cd} / \mathrm{m}^{2}$, ou seja, quando a percepção foi "Claro".

O fechamento das persianas ocorreu quando a luminância média da janela foi de $4.981 \pm 419 \mathrm{~cd} / \mathrm{m}^{2}$, ao passo que elas costumavam ficar abertas quando foi de $1.636 \pm 302 \mathrm{~cd} / \mathrm{m}^{2}$, sendo apresentado no gráfico de dispersão da Figura 15. 
Quadro 4 - Relação entre o DGI e o acionamento das lâmpadas e das persianas

\begin{tabular}{|c|c|c|c|}
\hline Índice DGI (sensação visual) & Percepção da iluminação & $\begin{array}{c}\text { Acionamento } \\
\text { das lâmpadas }\end{array}$ & $\begin{array}{c}\text { Acionamento } \\
\text { das persianas }\end{array}$ \\
\hline DGI $<17,7 \pm 0,8$ ("Imperceptível") & "Nem_Escuro/Nem_Claro" & Ligar & Aberto \\
\hline $\begin{array}{c}18,4 \pm 1,0<\text { DGI }<23,8 \pm 1,0 \\
\text { ("Perceptível") }\end{array}$ & "Claro" & Desligado & Aberto \\
\hline DGI $>23,9 \pm 1,0$ ("Desconfortável") & "Muito_Claro" & Ligar & Fechar \\
\hline
\end{tabular}

Figura 15 - A luminância média da janela (Lja) e o acionamento das lâmpadas e das persianas

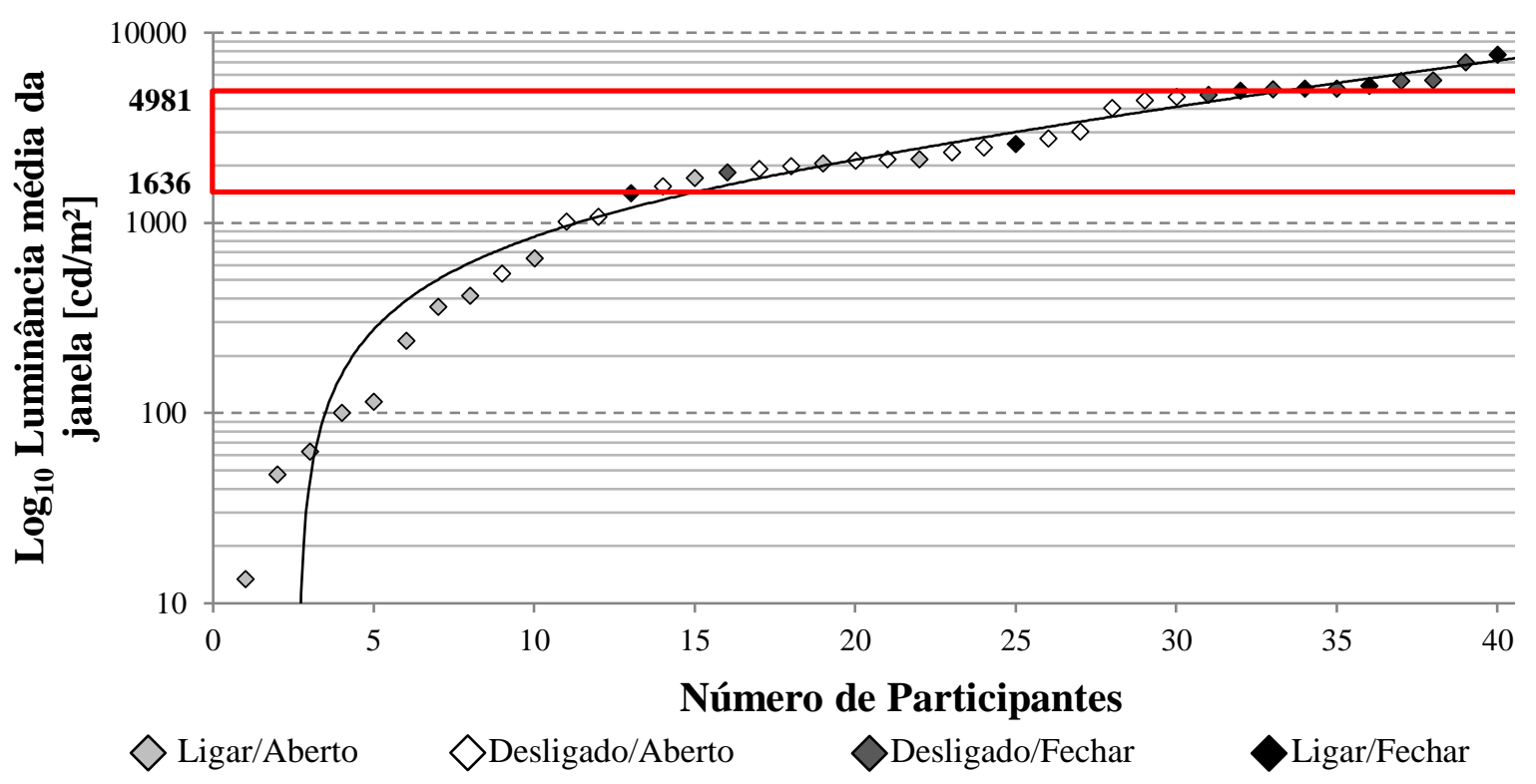

Nesse sentido, foi possível identificar um intervalo de luminância média da janela (Lja) que definiu a situação de lâmpadas desligadas e persianas abertas, o que na Figura 15 é observado nos valores de luminância $\mathrm{Lja}\left(\mathrm{cd} / \mathrm{m}^{2}\right)$ inseridos no quadrado vermelho.

Esse intervalo pode ser descrito da seguinte forma: quando a luminância média da janela foi inferior a 1.636 $\mathrm{cd} / \mathrm{m}^{2}$, ocorreu o acionamento das lâmpadas e as persianas permaneceram abertas; quando a luminância média da janela situou-se entre $1.636 \pm 302 \mathrm{~cd} / \mathrm{m}^{2}$ e $3.430 \pm 444 \mathrm{~cd} / \mathrm{m}^{2}$, as lâmpadas permaneceram desligadas e as persianas continuaram abertas. No intervalo de $3.430 \pm 444 \mathrm{~cd} / \mathrm{m}^{2}$ e $4.981 \pm 419 \mathrm{~cd} / \mathrm{m}^{2}$ sucederam-se algumas situações mistas (lâmpadas desligadas e persianas abertas e lâmpadas ligadas e persianas fechadas). No entanto, de forma expressiva, quando a luminância média da janela (Lja) foi superior a $4.981 \pm 419 \mathrm{~cd} / \mathrm{m}^{2}$, ocorreu o fechamento das persianas e, por conseguinte, o acionamento das lâmpadas (Quadro 5).

Também é interessante observar a luminância média da janela e a mediana para a situação de lâmpadas desligadas e persianas abertas, apresentadas no gráfico da Figura 16.

O gráfico da Figura 16 foi construído a partir das luminâncias médias da janela (Lja) dos participantes que deixaram as lâmpadas desligadas e as persianas abertas. Nota-se que a média $\left(2.413 \mathrm{~cd} / \mathrm{m}^{2}\right)$ e a mediana $\left(2.170 \mathrm{~cd} / \mathrm{m}^{2}\right)$ são relativamente próximas, o que indica pouca dispersão dos valores. Dessa forma, pode-se entender que esses valores (média e mediana) representam a luminância da janela para o máximo aproveitamento da iluminação natural no início da ocupação da sala, de forma que, dependendo do horário e das condições de iluminação no espaço interno, é possível protelar o acionamento das lâmpadas e, assim, diminuir o consumo de energia elétrica. 
Quadro 5 - Relação entre a luminância média da janela, a percepção da iluminação e o acionamento das lâmpadas e das persianas

\begin{tabular}{|c|c|c|c|}
\hline $\begin{array}{c}\text { Luminância média da janela } \\
\text { (Lja) }\left[\mathbf{c d} / \mathbf{m}^{2}\right]\end{array}$ & $\begin{array}{c}\text { Percepção da iluminação } \\
\text { da sala }\end{array}$ & $\begin{array}{c}\text { Acionamento } \\
\text { das lâmpadas }\end{array}$ & $\begin{array}{c}\text { Acionamento } \\
\text { das persianas }\end{array}$ \\
\hline $\mathrm{Lja}<1636 \pm 302$ & $\begin{array}{c}\text { "Muito_Escuro", } \\
\text { "Escuro", } \\
\text { Nem_Escuro/Nem_Claro" }\end{array}$ & Ligar & Aberto \\
\hline $1636 \pm 302<\mathrm{Lja}<3430 \pm 444$ & "Claro" & Desligado & Aberto \\
\hline $\mathrm{Lja}>4981 \pm 419$ & "Muito_Claro" & Ligar & Fechar \\
\hline
\end{tabular}

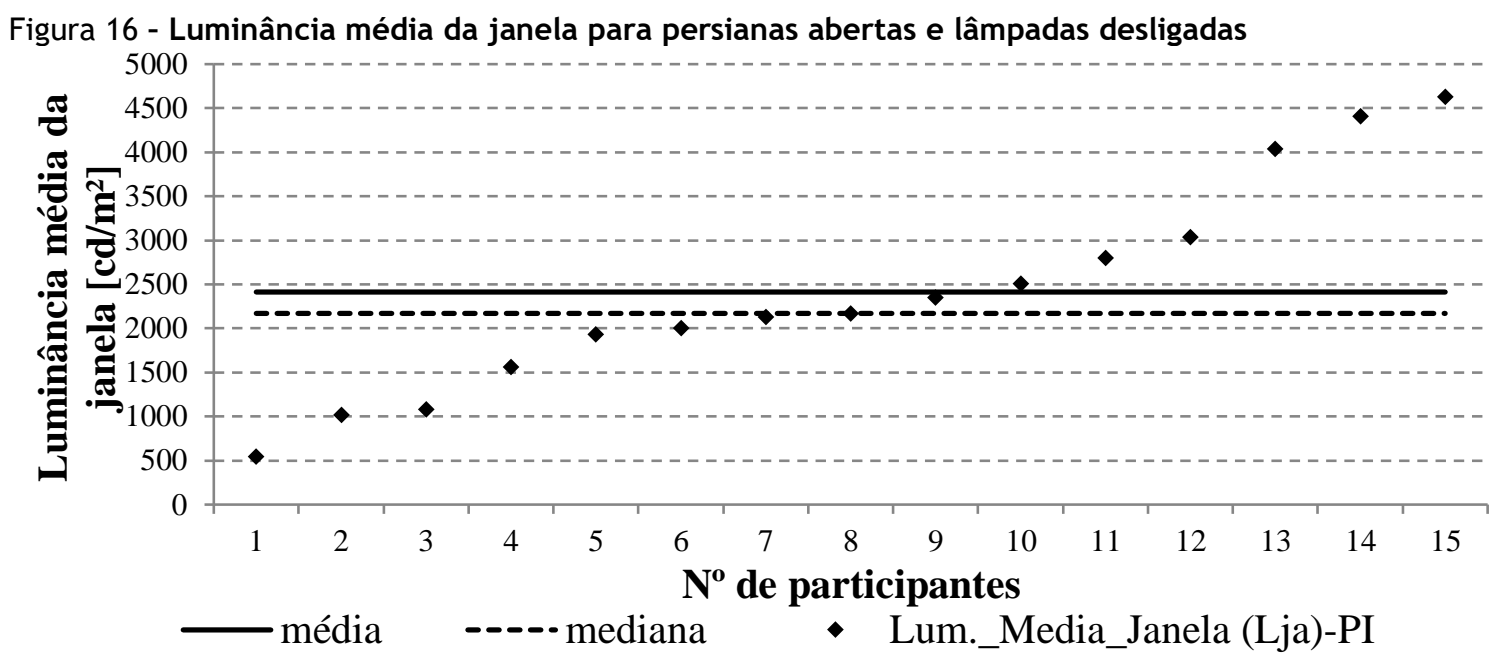

\section{Conclusões}

A pesquisa evidenciou intervalos para a caracterização da ocorrência do acionamento das lâmpadas e das persianas considerando a percepção da iluminação com base na luminância média da janela (Lja) e no índice de ofuscamento DGI.

O índice de ofuscamento DGP se mostrou pouco sensível ao subestimar valores frente a situações evidentes de desconforto devido possivelmente à dimensão da fonte perturbadora dentro do campo visual. Assim, recomenda-se mais estudos para demonstrar a influência das dimensões da fonte de ofuscamento nos valores de DGP.

Para o índice DGI, o intervalo definido para a situação de lâmpadas desligadas e persianas abertas foi entre $18,4 \pm 1,0$ e 23,8 $\pm 1,0$ ("Perceptível"), caracterizado pela percepção da iluminação de "Nem_Escuro/Nem_Claro" a "Claro". Sendo assim, quando DGI esteve abaixo de 18,4 \pm 1,0, a percepção da sala foi de "Escura" ou "Muito_Escura" e a atitude verificada foi de permanecer com as persianas abertas e ligar as lâmpadas; enquanto que para DGI acima de 23,8 $\pm 1,0$ a percepção foi "Muito_Claro", proporcionando eventos de persianas fechadas e lâmpadas ligadas.

Para a luminância média da janela (Lja), o intervalo que sugere a situação de lâmpadas desligadas e persianas abertas foi entre $1.636 \pm 302 \mathrm{~cd} / \mathrm{m}^{2}$ a $4.981 \pm 419 \mathrm{~cd} / \mathrm{m}^{2}$. Quando a Lja esteve abaixo de $1.636 \pm$ $302 \mathrm{~cd} / \mathrm{m}^{2}$, as ocorrências predominantes foram de lâmpadas ligadas e de persianas abertas. Para Lja acima de $4.981 \pm 419 \mathrm{~cd} / \mathrm{m}^{2}$, a percepção da iluminação foi definida como "Muito_Clara", e as persianas eram fechadas e as lâmpadas ligadas.

Ademais, é pertinente destacar que valores de luminâncias da janela em torno de $2.413 \mathrm{~cd} / \mathrm{m}^{2}$ sugerem um aproveitamento satisfatório da iluminação natural para a ocupação de um espaço. Certamente esse valor de luminância pode ser o "ponto de partida" para outras pesquisas até mesmo em outros modelos.

Esses resultados comportamentais obtidos a partir de indivíduos/observadores aplicam-se especificamente para a situação de ocupação de uma sala em que as condições de iluminação foram determinadas por uma janela "grande" que correspondia a $60 \%$ da área da parede (fechamento). Nesse sentido, para pesquisas 
futuras sugere-se realizar estudos em espaços de uso contínuo ocupados por uma a duas pessoas para comparar os resultados.

De forma relevante, conclui-se com este trabalho experimental que os intervalos para o índice DGI e a luminância média da janela (Lja) podem ser usados para construção de modelos comportamentais, ou seja, gráficos de probabilidade de acionamento de lâmpadas e de persianas, a serem aplicados em simulações computacionais que visam estudar o aproveitamento da luz natural e o consumo de energia elétrica em diferentes tipos de edificações.

\section{Referências}

ASSAF, L. O.; PEREIRA, F. O. R. Perspectivas de la eficiencia energética en la iluminación: desafíos para el desarrollo. ENCAC-COTEDI, v. 1, p. 26-42, 2003.

BOYCE, P.; HUNTER, C.; HOWLETT, O. The benefits of daylight through windows. New York: Lighting Research Center, 2003.

DORIA FILHO, U. Introdução à bioestatística: para simples mortais. São Paulo: Negócio Editora, 1999.

EKLUND, N. H.; BOYCE, P. R. The development of reliable, valid and simple Office Lighting Survey. Lighting Research Center, p. 855-880, 1995.

GOOGLE MAPS. [Mapa de Laguna]. Nota: imagem aérea do bairro Progresso do município de Laguna. 2019. Disponível em: https://www.google.com.br/maps/@-28.4775228,-48.7848354,265m/data=!3m1!1e3. Acesso em: 18 dez. 2019.

HARA, A. H. Controle pelo usuário dos sistemas de iluminação artificial e natural mediado pela percepção visual em espaços de transição e de permanência. Florianópolis, 2018. 255 f. Tese (Doutorado em Arquitetura e Urbanismo) - Programa de Pós-graduação em Arquitetura e Urbanismo, Universidade Federal de Santa Catarina, Florianópolis, 2018.

HISCOCKS, P. D. Measuring Luminance with a Digital Camera. 2011. Disponível em: https://www.ee.ryerson.ca/ phiscock/astronomy/light-pollution/luminance-notes-2.pdf. Acesso em: 30 abr. 2020.

HUNT, D. R. G. The use of artificial lighting in relation to daylight levels and occupancy. Building and Environment, v. 14, n. 1, p. 21-33, 1979.

INKAROJRIT, V. Balancing comfort: occupants' control of window blinds in private offices. Berkeley, 2005. 281 f. Tese (Doutorado em Arquitetura) - Departamento de Arquitetura, Universidade da Califórnia, Berkeley, 2005.

IWATA, T. et al. Discomfort caused by wide-source glare. Energy \& Buildings, v. 15, n. 16, p. 391-398, 1990.

JACOBS, A. High dynamic range imaging and its application in building research. Advances in Buiilding Energy Research, v. 1, n. 1, p. 177-202, 2007.

JAKUBIEC, J. A.; REINHART, C. F. A concept for predicting occupants' long-term visual comfort within daylit spaces. LEUKOS - Journal of Illuminating Engineering Society of North America, v. 12, n. 4, p. 185-202, 2016.

JAKUBIEC, J.; REINHART, C. The "adaptive zone": a concept for assessing discomfort glare throughout daylit spaces. Lighting Research and Technology, v. 44, n. 2, p. 149-170, 2012.

JASP TEAM. JASP: software de tratamento estatístico. Versão 0.9.2. 2018. Disponível em: https://jaspstats.org/download/. Acesso em: 21 nov. 2019.

KUMARAGURUBARAN, V. Hdrscope: documentation. Disponível em: http://courses.washington.edu/hdrscope/documentation/features.html. Acesso em: 12 dez. 2019.

KUMARAGURUBARAN, V.; INANICI, M. Hdrscope: high dynamic range image processing toolkit for lighting simulations and analysis. In: CONFERENCE OF INTERNATIONAL BUILDING PERFORMANCE SIMULATION ASSOCIATION, 13., Chambéry, 2013. Proceedings [...] Chambéry, 2013.

LOVE, J. A. Manual switching patterns in private offices. Lighting Research and Technology, v. 30, n. 1, p. 45-50, 1998. 
LYNES, J. A.; LITTLEFAIR, P. J.; SLATER, A. I. Preadaptation and manual switching. In: RIGHT LIGHT, 4., 1997. Proceedings [...] 1997.

MANICCIA, D. et al. Occupant use of manual lighting controls in private offices.pdf. Journal of the Illuminating Engineering Society, v. 34, p. 489-512, 1999.

MEDRI, W. Análise exploratória de dados. Londrina: Universidade Estadual de Londrina, 2011. (Apostila do Curso de Especialização "Lato Sensu" em Estatística).

PINEAULT, N.; DUBOIS, M. Effect of window glazing type on daylight quality: scale model study of a living room under natural sky. Journal of the Illuminating Engineering Society, v. 5, p. 83-99, 2008.

REA, M. S. Window blind occlusion: a pilot study. Building and Environment, v. 19, n. 2, p. 133-137, 1984.

REINHART, C. F.; WALKENHORST, O. Validation of dynamic RADIANCE-based daylight simulations for a test office with external blinds. Energy and Buildings, v. 33, n. 7, p. 683-697, 2001.

RUBIN, A. I.; COLLINS, B. L.; TIBBOTT, R. L. Window blinds as a potential energy saver-a case study. NBS Building Science Series, v. 112, p. 89, 1978.

SILVA, P. C.; LEAL, V.; ANDERSEN, M. Occupants interaction with electric lighting and shading systems in real single-occupied offices: Results from a monitoring campaign. Building and Environment, v. 64, p. 152-168, 2013.

VAN DEN WYMELENBERG, K. G. V. D. Visual comfort, discomfort glare, and occupant fenestration control: developing a research agenda. Leukos, v. 10, n. 4, p. 207-221, 2014.

VAN DEN WYMELENBERG, K. V. D.; INANICI, M.; JOHNSON, P. The effect of luminance distribution patterns on occupant preference in a daylit office environment. Journal of the Illuminating Engineering Society of North America, v. 7, p. 103-122, 2010.

WIENOLD, J.; CHRISTOFFERSEN, J. Evaluation methods and development of a new glare prediction model for daylight environments with the use of CCD cameras. Energy and Buildings, v. 38, n. 7, p. 743757, 2006.

YUN, G. Y.; KIM, H.; KIM, J. T. Effects of occupancy and lighting use patterns on lighting energy consumption. Energy and Buildings, v. 46, p. 152-158, 2012.

\title{
Agradecimentos
}

Os autores gostariam de agradecer aos familiares pelo suporte incondicional, aos participantes da pesquisa, à UDESC e à UFSC pelo apoio e colaboração no desenvolvimento da pesquisa, e ao CNPq - Brasil (Bolsa PQ 307179/2016-8) pelo suporte financeiro.

\section{Americo Hiroyuki Hara}

Departamento de Arquitetura e Urbanismo | Universidade do Estado de Santa Catarina | Rua Coronel Fernandes Martins, 270, Bairro Progresso | Laguna - SC - Brasil | CEP 88790-000 | Tel.: (48) 3647-7927 | E-mail: americo.hara@udesc.br

\section{Fernando Oscar Ruttkay Pereira}

Departamento de Arquitetura e Urbanismo | Universidade Federal de Santa Catarina | Campus Universitário Reitor João David Ferreira Lima, s/n, Trindade | Florianópolis - SC - Brasil | CEP 88040-900 | Tel.: (48) 3721-7080 | E-mail: ruttkay.pereira@ufsc.br

\author{
Ambiente Construído \\ Revista da Associação Nacional de Tecnologia do Ambiente Construído \\ Av. Osvaldo Aranha, $99-3^{\circ}$ andar, Centro \\ Porto Alegre - RS - Brasil \\ CEP 90035-190 \\ Telefone: +55 (51) 3308-4084 \\ Fax: +55 (51) 3308-4054 \\ www.seer.ufrgs.br/ambienteconstruido \\ E-mail: ambienteconstruido@ufrgs.br
}

